\title{
ELABORAÇÃO E CARACTERIZAÇÃO FÍSICO-QUÍMICA E SENSORIAL DE IOGURTE LIGHT PREBIÓTICO ADOÇADO COM MEL
}

\author{
Elaboration and physicochemical and sensory \\ characterization of prebiotic yogurt sweetened with honey
}

Álvaro Gustavo Ferreira da Silva ${ }^{1 *}$, Marcelino Maia Bessa ${ }^{l}$, Josefa Rosiane da Silva

\section{RESUMO}

Com a crescente preocupação da sociedade pela ingestão de alimentos saudáveis, a indústria alimentícia busca constantemente desenvolver produtos menos calóricos, associado à presença de ingredientes com propriedades funcionais. Logo, valendo-se da grande aceitação dos iogurtes, a indústria os tem utilizado como veículo para inclusão de compostos prebióticos. Dessa forma, objetivou-se com o presente trabalho a elaboração e caracterização, físico-química e sensorial, de iogurtes light adoçados com mel e suplementados com os prebióticos inulina e fruto-oligossacarídeos. Foram elaboradas três formulações: A (controle - ausente de prebióticos), $\mathrm{B}$ (com adição de $3 \%$ de inulina) e C (com 3\% de fruto-oligossacarídeos) que foram submetidas às análises físico-químicas de umidade, cinzas, $\mathrm{pH}$, acidez titulável e lipídeos e à análise sensorial de aceitação e intenção de compra. Estas permitiram obter resultados estatisticamente iguais para todos os parâmetros físicoquímicos avaliados, exceto a umidade. Quanto à análise sensorial, observou-se que, estatisticamente, a adição dos prebióticos não promoveu interferência significativa ( $\mathrm{p}$ $<0,05)$ nos parâmetros sensoriais avaliados, tornando as amostras bem aceitas, com índices de aceitabilidade superiores a 70\%, destacando a semelhança na aceitação das amostras suplementadas com prebióticos em relação à formulação-controle. Com relação à intenção de compra, a formulação $\mathrm{C}$ sobressaiu-se sob uma pequena vantagem numérica, porém não estatística, às demais formulações, sendo esta a mais viável para comercialização. Dessa forma, foi possível destacar a viabilidade da inclusão de prebióticos em formulações de iogurte light adoçados com mel, de

1 Instituto Federal de Educação, Ciência e Tecnologia do Rio Grande do Norte (IFRN), BR 405, KM 154, S/N, Bairro Chico Cajá, 59900-000, Pau dos Ferros, RN, Brasil. E-mail: gustavosilva012345@ gmail.com

* Autor para correspondência.

Recebido / Received: 28/04/2017

Aprovado / Approved: 05/09/2017 
modo a contribuir para a diversificação do setor lácteo e satisfazer a demanda da população por alimentos saudáveis.

Palavras-chave: fermentado lácteo; inulina; fruto-oligossacarídeos.

\begin{abstract}
With society's growing concern about eating healthy foods, the food industry constantly seeks to develop less calorie products, associated with the presence of ingredients with functional properties. Thus, taking advantage of the wide acceptance of yogurt, the industry has been using it as a vehicle for inclusion of prebiotic compounds. Therefore, the objective of this work was the preparation and characterization, physicochemical and sensory, of light yogurts sweetened with honey and supplemented with prebiotics inulin and fructooligosaccharides. Three formulations were prepared: A (control - free of prebiotics), B (with addition of $3 \%$ inulin) and $\mathrm{C}$ (3\% of fructooligosaccharides) that were submitted to physical and chemical analysis of moisture, ash, $\mathrm{pH}$, titratable acidity and lipids; and sensory analysis of acceptance and purchase intent. The results were statistically similar for all physical and chemical parameters assessed, except moisture. Concerning the sensory analysis, it was observed that, statistically, the addition of prebiotics did not cause significant interference $(\mathrm{p}<0.05)$ in the evaluated sensorial parameters, as all samples showed good acceptance with rates of over $70 \%$, highlighting the similarity acceptance of samples supplemented with prebiotics in relation to the formulationcontrol. Regarding the intention to purchase, formulation $\mathrm{C}$ stood out in a small numerical advantage, but not statistical, over the other formulations, being this the most viable for commercialization. Thus, it was possible to highlight the feasibility of including prebiotics in light yogurt sweetened with honey formulations in order to contribute to the diversification of the dairy sector and meet the population's demands for healthy food.
\end{abstract}

Keywords: starter cultures; inulin; fructooligosaccharides.

\section{INTRODUÇ̃̃O}

Tendo em vista o contemporâneo estilo de vida humano, que visa hábitos alimentares mais saudáveis, tem crescido cada vez mais a demanda por alimentos que não somente supram suas necessidades nutricionais, mas que também possuam funções benéficas à saúde e bem-estar de quem os consome (FONTES, 2013).

Nesse contexto, a indústria de laticínios tem aumentado consideravelmente sua competitividade no mercado, sendo uma das pioneiras na inovação de produtos alimen- tícios, buscando o desenvolvimento de alimentos com propriedades benéficas à saúde, os chamados alimentos funcionais. Em virtude dos seus diversos benefícios imunológicos e nutricionais, aliados à sua grande aceitação popular e praticidade de consumo, o iogurte compõe, mundialmente, o produto lácteo mais produzido e consumido desse segmento (COSTA et al., 2013; GRANATO, 2007; SANTOS; CANÇADO, 2009).

Obtido a partir da coagulação láctica do leite pela ação simbiótica dos Lactobacillus bulgaricus e Streptococcus thermophilus, o iogurte compõe um produto que, por si só, 
contém propriedades nutricionais bastante interessantes, como seu rico teor de cálcio e proteínas, além de minerais, como zinco e magnésio (MOLETA, 2006; ROCHA et al., 2008).

No âmbito dos alimentos funcionais, destacam-se também os prebióticos, definidos por Debon (2009), como componentes alimentares seletivamente fermentados por populações de bactérias desejáveis, tais como bifidobactérias e lactobacilos, que acarretam mudanças específicas na composição e/ou na atividade da microbiota gastrointestinal, afetando beneficamente o hospedeiro e contribuindo para sua saúde e bem-estar.

Dentre os prebióticos disponíveis no mercado, os mais estudados são a inulina e os fruto-oligossacarídeos (FOS). Quando ingeridos, ambos são capazes de fornecer diversos benefícios, como a melhoria das funções intestinais e da microbiota residente, aumento na absorção de minerais, como o cálcio (GIBSON; ROBERFROID, 2008), na prevenção de doenças, como hipertensão, diabetes e osteoporose (MUNDIN, 2008), além de estudos promissores que relatam possíveis diminuições do colesterol sanguíneo e redução nos riscos de câncer de cólon aos seus consumidores (PIMENTEL et al., 2012).

Além de suas propriedades funcionais, a inulina e o FOS também vêm ganhando cada vez mais destaque na indústria alimentícia por funcionarem, respectivamente, como substitutos para a gordura e, parcialmente, para o açúcar. Neste último caso, faz-se necessário a presença de outro agente adoçante para agir em conjunto com os FOS, garantindo assim os níveis de doçura desejáveis ao produto (FORTES; MUNIZ, 2010).

Neste contexto, a utilização do mel como adoçante é uma saída bastante conveniente, tendo em vista seu caráter de adoçante natural, por ser constituído basicamente de açucares e água. É uma alternativa viável por agregar um rico valor nutricional ao produto, bem como por possuir propriedades terapêuticas, por suas ações antibacteriana, antibiótica, anti-inflamatória, bioestimulante, energética etc. (LINS et al., 2015).

Outro aspecto relacionado com a saudabilidade dos produtos alimentícios é a preocupação com a ingestão excessiva de calorias, o que tem impulsionado a indústria alimentícia a desenvolver produtos com teor reduzido de gordura, ampliando o mercado de produtos light e diet, cada vez mais procurados pelos consumidores (RENSIS; SOUZA, 2008).

Desta forma, objetivou-se com o presente trabalho a elaboração e caracterização, físico-química e sensorial, de três formulações de iogurte light prebiótico adoçado com mel, de modo a satisfazer a demanda da população por produtos com menor valor calórico, associado à presença de ingredientes com propriedades funcionais.

\section{MATERIAL E MÉTODOS}

\section{Obtenção da matéria-prima}

Para a elaboração dos iogurtes, utilizouse mel de florada silvestre $\left(\right.$ Parati $^{\circledR}$ ) e leite UHT desnatado (Embaré ${ }^{\circledR}$ ), adquiridos no comércio da cidade de Pau dos Ferros - RN, além da cultura láctica Rica Nata Ricaferm (YRO2) e prebióticos: inulina e fruto-oligossacarídeos (FOS), adquiridos no comércio de Fortaleza - CE.

\section{Produção dos iogurtes}

Foram elaboradas três formulações que divergiam entre si pela presença ou não de prebióticos e pelo tipo utilizado. A formulação $\mathrm{A}$, controle - sem adição de prebióticos, formulação $\mathrm{B}$, contendo $3 \%$ de inulina, e formulação C, contendo 3\% de FOS. Os iogurtes foram elaborados seguindo a formulação básica descrita na Tabela 1 .

O processamento dos iogurtes foi realizado no laboratório de Processamento de Leites e Derivados do IFRN - Campus Pau 
dos Ferros, conforme metodologia utilizada por Nascimento (2014), adaptada para incremento de propriedade funcional e adequação da quantidade de ingredientes não lácteos adicionados, permitida pela legislação, que estabelece um limite máximo de $30 \%$, conforme apresentada na Figura 1.

Para esse trabalho, foram utilizados 6 litros de leite desnatado UHT, os quais foram aquecidos a $45{ }^{\circ} \mathrm{C}$, temperatura ótima para o crescimento da cultura lática, a qual foi adicionada na concentração de $0,01 \%$, conforme apresentado na Tabela 1, e homogeneizada. Em seguida, o conteúdo foi transferido para potes de polietileno, devidamente higienizados e colocados no equipamento estufa de temperatura controlada tipo BOD para iniciar a fermentação, a temperatura de $45^{\circ} \mathrm{C}$, permanecendo assim por aproximadamente 8 horas.

Após a fermentação, fez-se um breve resfriamento do produto a $7{ }^{\circ} \mathrm{C}$ e em seguida, realizou-se a quebra do coágulo formado e adição do mel. Nesse momento, fez-se também a adição dos prebióticos na proporção de $3 \%$ cada, sendo esta a concentração mínima para que o produto apresente alegações funcionais, consoante exigido pela Resolução n ${ }^{\circ} 19$, de abril de 1999 (BRASIL, 1999). Sendo a formulação B, com $3 \%$ de

Tabela 1 - Proporção dos ingredientes utilizados para a produção dos iogurtes

\begin{tabular}{cccc}
\hline INGREDIENTES & \multicolumn{3}{c}{ QUANTIDADE $(\%)$} \\
\cline { 2 - 4 } & $\mathrm{A}$ & $\mathrm{B}$ & $\mathrm{C}$ \\
\hline Leite desnatado UHT & 74,99 & 71,99 & 71,99 \\
Cultura Láctea & 0,01 & 0,01 & 0,01 \\
Mel & 25,00 & 25,00 & 25,00 \\
Inulina & - & 3,00 & - \\
FOS & - & - & 3,00 \\
\hline
\end{tabular}

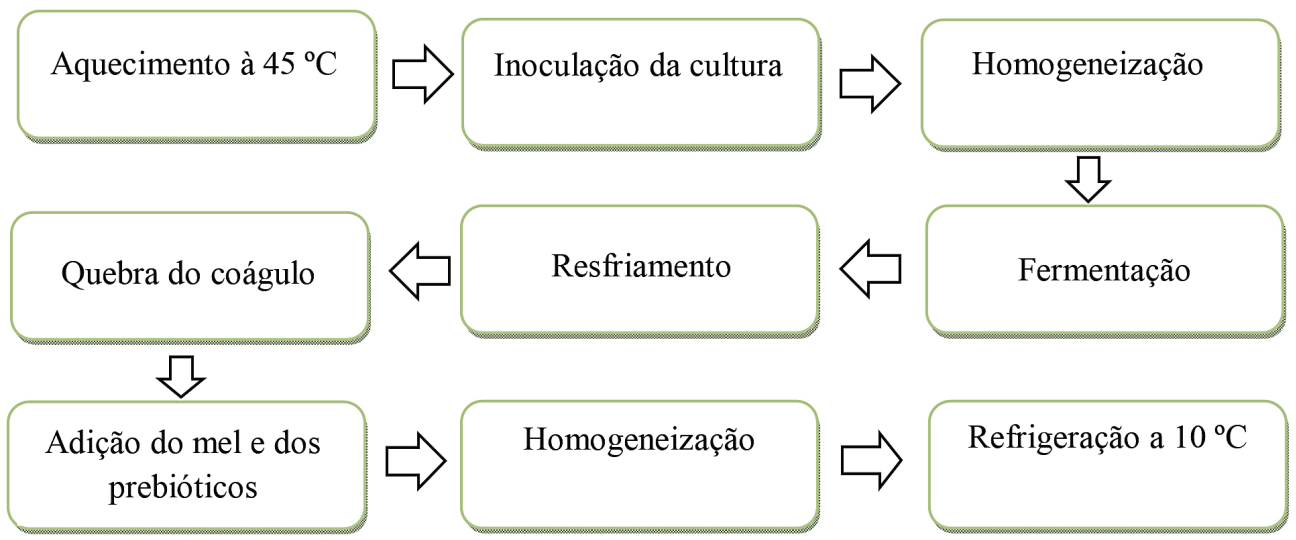

Fonte: Adaptado de Nascimento (2014).

Figura 1 - Fluxograma da elaboração dos iogurtes 
inulina, a formulação C, com 3\% de FOS, e permanecendo a formulação controle sem a adição de prebióticos. Por fim, o produto foi acondicionado sob refrigeração a $10{ }^{\circ} \mathrm{C}$, para posterior realização das análises físicoquímicas e sensorial.

\section{Caracterização físico-química dos iogurtes}

As formulações de iogurte foram submetidas às análises físico-químicas, em triplicata, nos Laboratórios de Análises Físicoquímicas do IFRN - Campus Pau dos Ferros. A análise de lipídeos de acordo com a metodologia utilizada por Folch et al. (1957), e $\mathrm{pH}$, umidade, cinzas e acidez titulável conforme recomendações do Instituto Adolfo Lutz (2008).

\section{Análise sensorial}

As amostras foram analisadas por 60 provadores voluntários não treinados, de ambos os sexos, consumidores de iogurte, compostos por alunos do IFRN - Campus Pau dos Ferros, na faixa etária de 15 a 22 anos.

Para cada provador, foi servido aproximadamente $25 \mathrm{~mL}$ de cada amostra em copos plásticos descartáveis de $50 \mathrm{~mL}$, codificados com números aleatórios de três dígitos. Os julgadores foram orientados a utilizarem água à temperatura ambiente entre as amostras, para a limpeza do palato. Para avaliar os atributos sensoriais das amostras, utilizou-se a ficha-resposta com os parâmetros sabor, cor, aroma, consistência e impressão global, com uma escala hedônica de 1 (desgostei muitíssimo) à 9 (gostei muitíssimo), e intenção de compra, com notas variando de 1 (com certeza não compraria) à 5 (com certeza compraria). Para concluir a avaliação sensorial, fez-se também o índice de aceitabilidade do produto a partir das notas obtidas no teste de aceitação, utilizando-se a metodologia de Peuckert et al. (2010), a partir da formula IA $(\%)=\mathrm{A} \times 100 / \mathrm{B}$, em que, $\mathrm{A}=$ nota média obtida para o produto $\mathrm{e}$ $\mathrm{B}=$ nota máxima dada ao produto.

\section{Análise estatística}

Os dados das análises físico-químicas e sensoriais foram analisados com auxílio do software Assistat 7.7 através da análise de variância (ANOVA), comparando-se as médias pelo teste de Tukey com nível de $5 \%$ de significância $(\mathrm{p}<0,05)$.

\section{RESULTADOS E DISCUSSÃO}

\section{Resultados da caracterização físico-quí- mica dos iogurtes}

Após a elaboração dos iogurtes, os mesmos foram submetidos à caracterização físicoquímica, conforme apresentado na Tabela 2 .

Os resultados médios para $\mathrm{pH}$, apresentados na Tabela 2, não apresentaram diferenças significativas entre as três formulações, ficando todas entre 4,35 e 4,37 e demonstrando a não interferência da inclusão dos prebióticos no $\mathrm{pH}$ dos iogurtes. Vale ressaltar também que todas as formulações enquadram-se na faixa recomendada pela Instrução Normativa $n^{\circ} 46$ de 24 de outubro de 2007 do MAPA, que estabelece o pH ideal para identidade e qualidade do iogurte entre 3,6 e 4,5 (BRASIL, 2007).

Os valores de $\mathrm{pH}$ obtidos neste estudo foram inferiores aos de Rensis e Souza (2008), que desenvolveram iogurtes light elaborados com adição de fibras de inulina e oligofrutose (quimicamente similar aos fruto-oligossacarídeos) e obtiveram um produto com média de $\mathrm{pH}$ em torno de 5,26. Entretanto, os resultados obtidos foram próximos aos encontrados por Reis et al. (2013) que estudaram a viabilidade técnica do iogurte tradicional de mel e obtiveram um $\mathrm{pH}$ médio de 4,47. 
Tabela 2 - Valores médios da caracterização físico-química das três formulações de iogurte

\begin{tabular}{ccccc}
\hline PARÂMETRO & A & B & C & $\begin{array}{c}\text { LEGISLAÇÃO } \\
\text { (BRASIL, 2007) }\end{array}$ \\
\hline pH & $4,37^{\mathrm{a}} \pm 0,046$ & $4,37^{\mathrm{a}} \pm 0,011$ & $4,35^{\mathrm{a}} \pm 0,015$ & $3,6-4,5$ \\
Acidez $(\%)$ & $0,93^{\mathrm{a}} \pm 0,000$ & $0,93^{\mathrm{a}} \pm 0,000$ & $0,93^{\mathrm{a}} \pm 0,025$ & $0,6-2,0$ \\
Umidade (\%) & $84,21^{\mathrm{a}} \pm 0,223$ & $83,19^{\mathrm{b}} \pm 0,070$ & $82,84^{\mathrm{b}} \pm 0,191$ & - \\
Cinzas $(\%)$ & $0,74^{\mathrm{a}} \pm 0,011$ & $0,74^{\mathrm{a}} \pm 0,034$ & $0,72^{\mathrm{a}} \pm 0,020$ & - \\
Lipídeos $(\%)$ & $0,44^{\mathrm{a}} \pm 0,014$ & $0,42^{\mathrm{a}} \pm 0,000$ & $0,43^{\mathrm{a}} \pm 0,014$ & Máx. 0,5 \\
\hline
\end{tabular}

* Formulação A (controle) - sem adição de prebióticos; Formulação B - com adição de 3\% de inulina e Formulação $\mathrm{C}$ - com adição de $3 \%$ de FOS.

**Valores expressos como média \pm desvio padrão.

Letras iguais numa mesma linha não diferem entre si de acordo com o teste de Tukey $(\mathrm{p}<0,05)$.

Quanto ao parâmetro de acidez, é notório a não diferença estatística entre as médias das amostras, que foram todas de $0,93 \%$, enquadrando-se nos requisitos físico-químicos exigidos pela legislação, que estabelece a acidez ideal em ácido láctico para leites fermentados de $0,9 \%$ a 2,0\% (BRASIL, 2007). Os valores de acidez apresentados no presente trabalho diferem dos mostrados por Moreira et al. (2014) que obtiveram média de $0,68 \%$ para iogurtes de maçã adoçados com mel, assim como dos valores expostos por Mundim (2008) que elaborou iogurtes suplementados com inulina e saborizados com frutos do cerrado, o qual obteve acidez que variou entre $0,48 \%$ e $0,72 \%$.

De acordo com a Instrução Normativa $\mathrm{n}^{\circ} 46$ de 24 de outubro do MAPA (BRASIL, 2007), não há recomendações mínimas de umidade e cinzas para produtos lácteos fermentados, tal qual o iogurte. Entretanto, é possível observar que os resultados para umidade diferiram estatisticamente, mostrando uma redução deste parâmetro nas formulações B e C, 83, 19 e 82,84\%, respectivamente, em relação ao controle $(84,21 \%)$. Esse fato pode ser explicado devido à capacidade dos prebióticos adicionados às formulações $\mathrm{B}$ e $\mathrm{C}$, de se ligarem à água, retendo-a e, como consequência, reduzindo a umidade do produto (PIMENTEL et al., 2012).

Em contra partida, os resultados encontrados não diferiram estatisticamente no teor de cinzas, em virtude do baixo conteúdo de cinzas presente nos prebióticos, apenas cerca de $0,2 \%$ (SILVA, 2010), obtendo a formulação controle $0,74 \%$ de cinzas e as formulações com adição de inulina e FOS com 0,74 e $0,72 \%$, respectivamente. Embora não tenham sido determinados os compostos individuais das cinzas, Queiroz (2014) afirma que os minerais encontrados em maior quantidade em produtos lácteos, como o iogurte, são o cálcio, magnésio, fósforo e potássio.

Os teores de umidade e cinzas deste trabalho são similares aos encontrados por Oliveira et al. (2007) que elaboraram iogurte desnatado (light) a base de leite de búfala e adoçado com mel, no qual obtiveram valores de $77,07 \%$ para umidade e $0,70 \%$ de cinzas. Os resultados também foram superiores aos obtidos por Hauly et al. (2005), que apresentaram $77,85 \%$ de umidade e $0,40 \%$ de cinzas ao produzirem iogurte de soja suplementado com fruto-oligossacarídeos, e valores relativamente próximos dos encontrados por Rensis e Souza (2008), que obtiveram de $83,96 \%$ e cinzas de $0,93 \%$ em seus iogur- 
tes light elaborados com adição de fibra de inulina e oligofrutose.

A porcentagem de lipídeos encontrada nas três formulações encontra-se em acordo com a legislação, que estabelece o máximo de $0,5 \%$ de matéria gorda para iogurtes desnatados (light) (BRASIL, 2007). Conforme expresso na Tabela 2 percebe-se que não houve diferença estatística entre as amostras, ficando todas entre $0,42 \%$ e $0,44 \%$. Fazendo-se notar, assim, a não interferência da incorporação dos prebióticos aos iogurtes quanto ao teor lipídico, uma vez que este é um composto ausente na composição dos prebióticos. Assim como no teor lipídico, também não houve interferência dos prebióticos na maioria dos parâmetros observados acima, exceto a umidade.

O conteúdo lipídico encontrado neste trabalho é ligeiramente inferior ao encontrado por Cunha Neto et al. (2005), ao elaborarem iogurte natural produzido com leite de búfala em sua versão light, no qual obtiveram um teor de $0,5 \%$ de matéria gorda. No entanto, foi superior ao encontrado por Vasconcelos (2010), que obteve $0,02 \%$ de lipídios em sua formulação controle no desenvolvimento de iogurtes light suplementados com farinha de yacon, e superior também, ao encontrado por Oliveira et al. (2007), que obteve um teor lipídico de 0,13\% ao desenvolver iogurte light a base de leite búfala e adoçado com mel.

\section{Resultados da análise sensorial}

As médias das notas de aceitabilidade dos atributos analisados na ficha de avaliação sensorial do iogurte são apresentadas na Tabela 3.

Conforme apresentado na Tabela 3, percebe-se que os prebióticos adicionados às formulações $\mathrm{B}$ e $\mathrm{C}$ não interferiram significativamente em nenhum dos atributos avaliados, permanecendo com aceitação semelhante à formulação controle. De modo geral, o produto apresentou médias de aceitação que na escala hedônica fazem referência a "gostei moderadamente", com exceção para o aroma, em que a maioria dos avaliadores julgaram o atributo como "gostei ligeiramente".

No quesito sabor, os resultados encontrados foram superiores aos obtidos por Moura et al. (2012) que avaliaram sensorialmente formulações de iogurtes adoçados com mel e com açúcar, e obtiveram o parâmetro de sabor com média de 5,56. Os resultados foram superiores também, aos reportados por Reis et al. (2013), que estudaram a viabilidade técnica do iogurte tradicional de mel, obtendo uma média de aceitação para o sabor, de 6,42. Porém, foram inferiores aos reportados por Lins et al. (2015), que compararam o efeito adoçante do mel e do açúcar em formulações de iogurte de maracujá, obtendo uma média de aceitação de

Tabela 3 - Médias dos parâmetros sensoriais realizadas para as formulações de iogurte

\begin{tabular}{cccc}
\hline & A & B & C \\
\hline Sabor & $7,2^{\mathrm{a}} \pm 1,392$ & $7,2^{\mathrm{a}} \pm 1,505$ & $7,2^{\mathrm{a}} \pm 1,638$ \\
Cor & $7,7^{\mathrm{a}} \pm 0,922$ & $7,8^{\mathrm{a}} \pm 0,994$ & $7,8^{\mathrm{a}} \pm 0,917$ \\
Consistência & $7,4^{\mathrm{a}} \pm 1,401$ & $7,5^{\mathrm{a}} \pm 0,707$ & $7,5^{\mathrm{a}} \pm 1,268$ \\
Aroma & $6,9^{\mathrm{a}} \pm 1,436$ & $6,8^{\mathrm{a}} \pm 1,414$ & $6,6^{\mathrm{a}} \pm 1,521$ \\
Impressão Global & $7,8^{\mathrm{a}} \pm 0,923$ & $7,8^{\mathrm{a}} \pm 0,988$ & $7,9^{\mathrm{a}} \pm 0,944$ \\
\hline
\end{tabular}

* Formulação A (controle) - sem adição de prebióticos; Formulação B - com adição de 3\% de inulina e Formulação C - com adição de $3 \%$ de FOS.

**Valores expressos como média \pm desvio padrão.

Letras iguais numa mesma linha não diferem entre si de acordo com o teste de Tukey $(\mathrm{p}<0,05)$. 
8,17 e 8,47 , respectivamente, destacando a preferência do consumidor por iogurtes adoçados com açúcar do que mesmo com mel, apesar de sua maior vantagem nutricional.

Para a cor, que é um dos primeiros atributos avaliados pelo consumidor e que influencia diretamente na aceitação e na decisão de compra do produto (QUEIROZ, 2014), não foi notada diferença significativa ( $p$ $<0,05)$ na aceitação das amostras, sendo elas classificadas pelos julgadores como "gostei moderadamente" na escala hedônica. Entretanto, as amostras B e C, suplementadas com inulina e FOS, respectivamente, ainda obtiveram uma ligeira vantagem na aceitação, se comparadas com a formulação controle.

Quanto à consistência, apesar de também não ter havido diferença significativa entre as formulações, é visível um ligeiro aumento numérico na aceitação das amostras B e C, suplementadas com inulina e FOS, respectivamente. Isso ocorre, provavelmente, em virtude dos prebióticos apresentarem grupos (OH-) disponíveis, os quais ligam-se facilmente com a água, promovendo uma maior viscosidade e tornando o produto mais espesso (KUNTZ et al., 2013). Em oposição ao explanado por Antunes et al. (2004) ao afirmarem que, de modo geral, produtos com teor reduzido de gordura tendem a apresentar consistência mais frágil que os integrais, em virtude da capacidade da gordura de fornecer ao produto uma maior cremosidade, a consistência foi um dos parâmetros melhor avaliados no presente trabalho, obtendo média referente a "gostei moderadamente" na escala hedônica. As médias de consistência obtidas neste trabalho foram ligeiramente superiores aos de Cunha Neto et al. (2005) ao desenvolverem iogurtes naturais produzidos com leite de búfala, e obterem média de aceitação de 7,1 em sua versão integral.

Para o aroma, todas as amostras também obtiveram resultados estatisticamente iguais, sendo enquadradas pelos julgadores como "gostei ligeiramente" na escala hedônica e constando a não interferência dos prebióticos. Dentre os atributos estudados na ficha de aceitação sensorial, este foi o que obteve menor aceitação, o que pode ser explicado, provavelmente, pela fixação do aroma residual do mel ao produto final, uma vez que em geral, é um ingrediente de baixa preferência pelo brasileiro, para adoçar os alimentos (MOURA, 2012) e principalmente por ter sido utilizado em alta concentração (25\%).

A impressão global estudada, referente à avaliação geral do produto, também não apresentou diferença significativa $(p<0,05)$ entre as formulações, fazendo-se notar a não interferência dos prebióticos nos atributos sensoriais avaliados e, assim, constatando a

Tabela 4 - Índice de aceitabilidade dos iogurtes

\begin{tabular}{cccc}
\hline & A & B & C \\
\hline Sabor & 80,0 & 80,0 & 80,0 \\
Cor & 85,5 & 86,6 & 86,6 \\
Consistência & 82,2 & 83,3 & 83,3 \\
Aroma & 76,6 & 75,5 & 73,3 \\
Impressão Global & 86,6 & 86,6 & 87,7
\end{tabular}

* Formulação A (controle) - sem adição de prebióticos; Formulação B - com adição de 3\% de inulina e Formulação $\mathrm{C}$ - com adição de $3 \%$ de FOS.

**Valores expressos como média \pm desvio padrão.

Letras iguais numa mesma linha não diferem entre si de acordo com o teste de Tukey $(\mathrm{p}<0,05)$. 
viabilidade da inulina e FOS como ingredientes funcionais a serem inseridos às formulações de alimentos. Como observado na Tabela 3, as três formulações classificaram-se na faixa de "gostei moderadamente" na escala hedônica.

$\mathrm{O}$ índice de aceitabilidade do produto, realizado segundo metodologia de Peuckert et al. (2010), está apresentado na Tabela 4.

De acordo com Peuckert et al. (2010), um produto de boa aceitação, deve apresentar um índice de aceitabilidade igual ou superior a $70 \%$ e desta forma, pode-se inferir, com base nos resultados apresentados na Tabela 4, que todas as formulações de iogurte obtiveram aceitação satisfatória, com índices variando entre $73,3 \%$ e $87,7 \%$, destacando-se que as amostras com prebióticos, em geral, apresentaram maiores índices, com exceção, para o atributo aroma, no qual sobressaiu-se a formulação controle, com 76,6\%.

Para finalizar a avaliação sensorial dos iogurtes formulados, verificou-se também a intenção de compra dos produtos, conforme apresentado na Tabela 5.

Tabela 5 - Intenção de compra dos iogurtes

\begin{tabular}{cc}
\hline FORMULAÇÕES & $\begin{array}{c}\text { INTENÇÃO } \\
\text { DE COMPRA }\end{array}$ \\
\hline A & $3,63^{\mathrm{a}} \pm 1,057$ \\
B & $3,60^{\mathrm{a}} \pm 1,060$ \\
$\mathrm{C}$ & $3,66^{\mathrm{a}} \pm 0,950$
\end{tabular}

* Formulação A (controle) - sem adição de prebióticos; Formulação B - com adição de $3 \%$ de inulina e Formulação C - com adição de $3 \%$ de FOS.

**Valores expressos como média \pm desvio padrão. Letras iguais numa mesma coluna não diferem entre si de acordo com o teste de Tukey $(\mathrm{p}<0,05)$.

Os iogurtes desenvolvidos obtiveram médias correspondentes a "talvez comprasse e talvez não comprasse", destacando o potencial do produto desenvolvido neste estudo, caso estivesse disponível no mercado. Embora não tenha diferença estatística $(p<0,05)$ entre os iogurtes, observa-se um pequeno destaque para a formulação $\mathrm{C}$, que apresentou a maior média $(3,66)$.

Os resultados demonstram que a adição de prebióticos não resultou em efeitos negativos quanto à qualidade sensorial dos produtos, havendo inclusive uma maior aceitação geral para as formulações contendo esses compostos funcionais, o que demonstra a viabilidade da adição de inulina e frutooligossacarídeos em iogurtes, contribuindo para o desenvolvimento de produtos com maior apelo nutricional e melhores características sensoriais.

\section{CONCLUSÕES}

O estudo desenvolvido permitiu comprovar a viabilidade da inulina e dos FOS como potenciais ingredientes com propriedades funcionais a serem inclusos em formulações de iogurtes, ressaltando a não interferência dos mesmos na maioria dos parâmetros físico-químicos avaliados, atendendo à legislação vigente. Do ponto de vista sensorial, comprovou-se que o produto foi bem aceito pelos provadores e que, estatisticamente, os prebióticos não interferiram nas características sensoriais estudadas, ficando as amostras B e C com aceitação similar à formulação controle.

De uma forma geral, a formulação C, com adição de 3\% de FOS, obteve uma ligeira vantagem numérica, porém não estatística, em relação às demais, tanto na aceitação, quanto na intenção de compra. Contudo, percebe-se que as três formulações são viáveis na diversificação do setor lácteo, contribuindo para satisfazer a demanda da população por alimentos funcionais e com índices de intenção de compra aceitáveis para comercialização.

\section{REFERÊNCIAS}

ANTUNES, A. E. C. et al. A. Iogurtes desnatados probióticos adicionados de concentrado proteico do soro de leite: perfil de 
textura, sinérese e análise sensorial. Revista Alimentos e Nutrição, Araraquara, v. 15, n. 2, p.107-114, 2004.

BRASIL. Agência Nacional de Vigilância Sanitária. Resolução n ${ }^{\circ} 19$, de 30 de abril de 1999. Aprova o Regulamento Técnico de Procedimentos para Registro de Alimento com Alegação de Propriedades Funcionais ou de Saúde em sua Rotulagem. Diário oficial da República Federativa do Brasil. Brasília, DF, 03 maio 1999.

BRASIL. Ministério da Agricultura, Pecuária e Abastecimento (MAPA). Portaria $n^{\circ} 46$, de 23 de novembro de 2007. Aprova o Regulamento Técnico de Identidade e Qualidade de Leites Fermentados. Diário oficial da República Federativa do Brasil. Brasília, DF, 24 de outubro de 2007, Seção 1, pág. 4, 2007.

COSTA, M. P. et al. Leite Fermentado: Potencial Alimento Funcional. Revista enciclopédia conhecer, Goiânia, v. 8, n. 16, p. 1338-1338, jul. 2013.

CUNHA NETO, O. C. et al. Avaliação Físico-Química e Sensorial do Iogurte Natural Produzido Com Leite de Búfala Contendo Diferentes Níveis de Gordura. Revista de Ciência e Tecnologia de Alimentos, Campinas, v. 1, n. 1, p.448-453, 11 ago. 2005.

DEBON, J. Emprego da Microfiltração Tangencial na Obtenção de Leite Fermentado Prebiótico. 2009. 120 f. Dissertação (Mestrado de Engenharia de Alimentos.) - Universidade Federal de Santa Catarina, Florianópolis, 2009.

FOLCH, J. et al. A simple method for the isolation and purification of total lipids from animal tissues. Journal Biological Chemistry, v. 226, n. 1, p. 497-509, 1957.

FONTES, C. P. L. M. Produção de oligossacarídeos pré-bióticos em sucos de frutas.
119 f. 2013. Tese (Doutorado em Biotecnologia Industrial) - Universidade Federal do Ceará, Fortaleza.

FORTES, R. C.; MUNIZ, L. B. Efeitos da suplementação dietética com frutooligossacarídeos e inulina no organismo humano: estudo baseado em evidências. Revista Brasileira de Ciências Saúde, Brasília, v. 3, n. 20, p. 241-252, 2010.

GIBSON, G. R.; ROBERFROID, M. B. Concluding remarks. In: GIBSON, G. R.; ROBERFROID, M. B. Handbook of prebiotics. London: CRC Press, p. 471-473, 2008.

GRANATO, D. Leites Fermentados: algumas considerações. Revista Leites \& Derivados, São Paulo, v. 16, n. 100, p. 16-33, 2007.

HAULY, M. C. O. et al. Suplementação de iogurte de soja com frutooligossacarídeos: características probióticas e aceitabilidade. Revista de Nutrição, Campinas, v. 5, n. 18, p. 613-622, 2005.

INSTITUTO ADOLFO LUTZ. Normas Analíticas do Instituto Adolfo Lutz. Métodos químicos e físicos para análise de alimentos. $4^{\mathrm{a}}$ ed. São Paulo: IMESP, 2008.

KUNTZ, M. G. F. et al. Characteristics of prebiotic food products containing inulin. British Food Journal, v. 115, n. 2, p. 235-251, 2013.

LINS, A. D. F. et al. Impacto sob a aceitação sensorial de iogurtes enriquecidos com polpa de maracujá adoçados com açúcar e com mel. Revista Agropecuária Técnica, v. 36, n. 1, p. 103-108, 2015.

MOLETA, C. B. Elaboração de iogurte caseiro e avaliação físico-química, em relação a iogurte industrializado. 2006. 12p. Trabalho de Conclusão de Curso (Graduação em Nutrição) - Faculdade Assis Gurgacz, Cascavel, 2006. 
MOREIRA, I. S. et al. Elaboração e Avaliação da Qualidade de Iogurtes de Maçã Adoçados com Sacarose e com Mel. Revista Verde de Agroecologia e Desenvolvimento Sustentável, Mossoró, v. 9, n. 1, p.10-14, 2014.

MOURA, R. L. et al. Iogurte de leite de cabra: Processamento e avaliação sensorial entre dois tratamentos. In: CONGRESSO NORTE E NORDESTE DE PESQUISA E INOVAÇÃO, 7. 2012, Palmas. Anais... Palmas: IFTO, 2012.

MUNDIM, S. A. P. Elaboração de iogurte funcional com leite de cabra, saborizado com frutos do cerrado e suplementado com inulina. 2008. 133 f. Dissertação (Mestrado em Tecnologia de Processos Químicos e Bioquímicos) - Universidade Federal do Rio de Janeiro, Rio de Janeiro, 2008.

NASCIMENTO, R. M. Elaboração e comparação sensorial entre os iogurtes sabor acerola adoçado com açúcar e adoçado com mel. 2014. 37 f. Trabalho de Conclusão de Curso (Técnico em alimentos) - Instituto Federal de Educação, Ciência e Tecnologia do Rio Grande do Norte.

OLIVEIRA, M. G. de et al. Análise microbiológica, físico-química e sensorial do iogurte de leite búfala integral e desnatado adoçado com mel de abelha. In: ENCONTRO DE PROFISSIONAIS DA QUÍMICA DA AMAZÔNIA, 10., 2007, Belém, PA. Recursos naturais: uma reflexão para os profissionais da química. Belém, PA: Anais... Belém: Conselho Regional de Química da 6 ${ }^{\mathrm{a}}$ Região, 2007.

PEUCKERT, Y. P. et al. Caracterização e aceitabilidade de barras de cereais adicionadas de proteína texturizada de soja e camucamu (Myrciaria dubia). Revista Alimentos e Nutrição, Araraquara, v. 21, n. 1, p. 147-152, 2010.

PIMENTEL, T. C. et al. Aspectos funcionais, de saúde e tecnológicos de frutanos tipo inulina. Boletim do Centro de Pesquisa e Processamento de Alimentos, Curitiba, v. 30, n. 1, p. 103-118, 2012.

QUEIROZ, M. B. Elaboração e Caracterização Físico-Química e Sensorial de Iogurte Prebiótico de Acerola. 2014. 42 f. TCC (Técnico em Alimentos) - Instituto Federal de Educação, Ciência e Tecnologia do Rio Grande do Norte, Pau dos Ferros, 2014.

REIS, K. T. M. G. et al. Estudo e Avaliação Sensorial da Viabilidade Técnica do Iogurte Tradicional de Mel, Acrescido de Uma Calda Natural de Goiaba, Como Forma de Agregar Valor à Dois Produtos da Mesorregião do Sertão Alagoano. Revista Verde de Agroecologia e desenvolvimento sustentável, v. 3, n. 2, p. 8 , 2013.

RENSIS, C. M. V. B.; SOUZA, P. F. F. Análise Sensorial De Iogurtes Light Elaborados com Adição de Fibras de Inulina e Oligofrutose. Fazu em Revista, Uberaba, v. 1, n. 5, p. 68-72, 2008.

ROCHA, C. et al. Elaboração e Avaliação de Iogurte Sabor Frutos do Cerrado. Revista Centro de Pesquisa e Processamento de Alimentos, Curitiba, v. 26, n. 2, p. 255-266, 2008.

SILVA, F. B. Efeitos Da Inulina Nas Propriedades Físico Químicas, Sensoriais e De Textura De Embutido De Peito De Peru Defumado. 2010. 73 f. Dissertação (Mestrado em Ciência dos Alimentos) - Universidade Federal de Santa Catarina, Florianópolis, 2010.

VASCONCELOS, C. M. Caracterização físicoquímica e sensorial de iogurte "Light" com farinha de Yacon (Smallanthus sonchifolius). 2010. 56 f. Dissertação (Mestrado de Ciência e Tecnologia de Alimentos) - Universidade Federal de Viçosa, Viçosa, 2010. 